\title{
Transgresión de las identidades tradicionales de género mediante la representación gráfica de mujeres protagonistas para videojuegos desarrollada por niños y niñas
}

\section{Transgression of traditional gender identities through the graphical representation of women protagonists video game developed by children}

\author{
Luis Claudio Cortés-Picazo \\ Universidad Metropolitana de Ciencias de la Educación. Chile. \\ luis_clecu@yahoo.com
}

Recibido: 22 de abril de 2015

Aprobado: 22 de junio de 2016

\begin{abstract}
Resumen
El artículo identifica y analiza el discurso predominante que poseen 12 niños y 7 niñas de $7^{\circ}$ y $8^{\circ}$ año básico pertenecientes a 4 establecimientos educacionales en la ciudad de Talca en Chile, en torno a la transgresión de las identidades tradicionales de la mujer en los videojuegos. Para ello durante el $1^{\circ}$ semestre del año 2014 al interior de un programa de formación de profesores/as en Artes Visuales se implementa una estrategia didáctica centrada en la expresión gráfica denominada "Crea tu propia personaje para videojuego". Haciendo partícipes a niños y niñas junto a profesionales en formación de una propuesta metodológica basada en la Investigación-Acción enmarcada en las prácticas profesionales. Concluyendo tras el análisis semántico de dibujos y relatos, que las imágenes representativas de la mujer en los videojuegos transgreden las identidades tradicionales de género al interior de un marco androcéntrico predominante.
\end{abstract}

Palabras clave: infancia, género, videojuegos, pedagogía queer, artes visuales.

Cortés-Picazo, L.C. (2016): Transgresión de las identidades tradicionales de género mediante la representación gráfica de mujeres protagonistas para videojuegos desarrollada por niños y niñas. Arte, Individuo y Sociedad, 28(3) 459-473

\begin{abstract}
The article identifies and analyzes the dominant discourse that have 12 boys and 7 girls 7 th and 8 th base year belonging to 4 educational establishments in the city of Talca in Chile, around the transgression of traditional identities of women in the video games. To do this during the 1st half of 2014 into a training program for teachers / Visual Arts as a teaching strategy that focuses on graphical expression called "Create your own character for video game" is implemented. By involving children alongside professionals in forming a methodological proposal based on Action Research framed in professional practices. Concluding after semantic analysis of drawings and stories, that representative images of women in video games transgress traditional gender identities into a dominant androcentric framework. Keywords: childhood, gender, video games, queer pedagogy, visual arts.
\end{abstract}


Sumario: 1. Introducción, 2. Marco Teórico: una expresión grafica cimentada en el feminismo queer, 3. Metodología: "Crea tu propia personaje para video-juego", 3.1. Investigación-Acción: Ciclo, Roles, Espacios Pedagógicos y Técnicas de recogida de datos, 3.2. Identificación de la idea inicial, 3.3. Reconocimiento y revisión de idea, 3.4. Hipótesis de trabajo, 3.5. Estructura de plan general, 3.6. Reconocimiento y revisión de sus efectos, 3.6.1. Subversión de las identidades tradicionales de género al interior del marco performativo de sanción heterosexual: el bien y el mal, 3.6.2. Estética predominante Japonesa y oposición binaria entre pares según género de informantes claves, 3.6.3. La ficción como estructura narrativa de los videojuegos, 4 . Conclusiones. Referencias.

\section{Introducción}

Reflexionar sobre las imágenes de mujer presentes en los videojuegos (Cassell \& Jenkins, 2000; Imbert, 2008; Volnovich, 2008; Guarinos, 2011) implica aproximar críticamente la Cultura Visual hacia procesos de enseñanza aprendizaje de las Artes Visuales centrados en el feminismo queer. Perspectiva crítica que analiza la construcción generizada de cuerpos sexuados en la Cultura Visual bajo el correlato sexo-género (Rubin, 2008; Butler, 2001, 2007). Cuestionando procesos culturales que sancionan y reiteran las construcciones identitarias de género sobre cuerpos reales y ficticios, perpetuando estereotipos de género cimentados en la cultura falogocéntrica.

De hecho cabe destacar que las imágenes representativas de la mujer en los videojuegos han sido objeto de transformaciones identitarias de género una vez iniciado el siglo XXI (Kennedy, 2002; Mikula, 2003; Fantone, 2003; Mendizábal, 2004; Gil-Juarez et.al., 2010). Siendo los procesos de digitalización de imágenes en la Cibercultura (Levy, 2007) las que han subvertido el correlato tradicional de sexo y género en la representación de los cuerpos. En donde la digitalización de representación de los cuerpos en la industria de los videojuegos, han conformado los mecanismos de transgresión de las fronteras binarias de género (Femenino/Masculino). Empleando recursos tales como el hiperrealismo estético y funcional (King \& Krzywinska, 2006), sometiendo imágenes generizada de cuerpos a procesos de codificación que sintetizan la suma de elementos acumulados traducidos en una serie de dígitos: puntos o píxeles (Schultz, 2006). Obteniendo como resultado imágenes digitales de cuerpos cuyos géneros no se condicen con su sexo en términos tradicionales, bajo las coordenadas del plano cartesiano y su consecuente variación cromática generadora de la tercera dimensión, según Levy (Levy, 2007). Problematizando de este modo la masculinización y feminización de cuerpos ficticios cuyos significados se aproximan preferentemente al cyborg (Haraway, 1995), enmarcados en contextos de espectacularización (Darley, 2002) e hiperbolización (Butler, 2007) de cuerpos reales.

Diluyendo de este modo las fronteras tradicionales de género que excluyen o subsumen las imágenes representativas de la mujer bajo la alteridad binaria de lo masculino y lo femenino. Posibilitado en la Cibercultura una mayor visibilización de la mujer que asume roles destinados tradicionalmente al hombre. Lo que reviste alcances de igualdad ante la inclusión cultural de imágenes representativas de la mujer gracias a la tecnología, según el Tecnofeminismo o Tecnoptimismo (Wajcman, 2008, 2012).

Sin embargo, cabe señalar que dicha presunción de igualdad en la representación no tradicional de género tras los procesos de digitalización y creación de imágenes de lo femenino es objeto de cuestionamiento. De hecho para Volnovich (2010) el 
grado de innovación que conlleva dicha igualdad en la representación está por verse, independientemente que a lo largo de la historia de los videojuegos han aparecido figuras femeninas tales como Lara Croft en Tomb Rider y Bombón, Bellota y Burbuja en las Chicas Superpoderosas.

Problemática ante la cual se torna necesario implementar espacios para la reflexión crítica al interior de procesos formales de escolarización, e indagar el rol asumido por niños y niñas en calidad de consumidores/as de imágenes generizadas en la Cultura Visual (Buckingham, 2000; Hernández, 2000; Wilson \& Wilson, 2004; Paulino, Zarza, Serrano, 2011). Con el objeto de estilar los significados atribuidos a las imágenes representativas de la mujer en la Cibercultura, muy particularmente aquellas presentes en los videojuegos digitales que niños y niñas consumen habitualmente en calidad de videojugadores/as.

Es por ello, que se propone el diseño de una estrategia didáctica centrada en la expresión gráfica de niños y niñas en contextos de escolarización al interior de un programa de formación de profesores y profesoras en artes visuales. De tal modo analizar críticamente el discurso predominante que niños y niñas poseen respecto de la identidad de género destinada a la mujer en los videojuegos. Articulando metodológicamente la teoría y la práctica educativa al interior del proceso formativo de profesionales en formación, mediante una didáctica cimentada en el feminismo queer.

Tras lo cual emerge el siguiente objetivo principal: "Identificar y analizar el discurso predominante elaborado por niños y niñas ante las imágenes representativas de la mujer en los videojuegos".

\section{Marco Teórico: una expresión grafica cimentada en el feminismo queer}

A raíz de la problemática anteriormente expuesta cabe resaltar que Cortés (2014) esclarece a partir de la expresión gráfica de niños y niñas que el feminismo queer es la perspectiva de análisis crítico mayormente pertinente para reflexionar en torno a las prácticas pedagógicas centradas en los conceptos de mujer emanados desde la Cultura Visual. Sobre todo al evidenciar que las representaciones gráficas de figuras heroicas masculinas y femeninas desarrolladas por niños y niñas, son productos del consumo de imágenes generizadas representativas de hombres y mujeres que sancionan desde la primera infancia la heteronormatividad.

De hecho la perspectiva feminista queer (Butler, 2007) y sus planteamientos respecto de la sanción y reiteración de la heteronormatividad en contextos escolares, esclarece que los procesos de enseñanza aprendizaje de las artes visuales reproducen identidades de género construidas por la industria cultural. Debido a que sus procesos performativos obedecen a leyes estéticas de mercado cuyas imágenes sintéticas (Schultz, 2006) de lo femenino, son producto de procesos de hiperbolización corpórea (Nead, 1992; Butler, 2007) utilizando el cuerpo como signo/disfraz hiperfeminizado al reapropiarse de los signos de lo masculino en forma de imitación (Imbert, 2008). Cuya presencia en los videojuegos permite su fácil acceso y consumo por parte niños y niñas fuera de contextos escolares ajenos al desarrollo de capacidades reflexión crítica al interior del aula.

Razón suficiente para comprender las implicaciones pedagógicas de lo queer (Zafra, 2015) a través de la expresión grafica en contextos escolares, cuya reiteración y sanción de normas de género condicionan la libertad expresiva (Vitta, 2003). Requiriendo de 
estrategias de enseñanza aprendizaje cimentadas en el feminismo queer para efectos de garantizar en niños y niñas las condiciones que faciliten su ejercicio de participación social y el acceso a la información y la entretención (Torres y Salazar, 2006). Dotándoles como productores/as en lugar de consumidores/as de la Cultura Visual (Buckingham, 2000, Hernández, 2000, III Congreso de arte infantil, U.C.M., 2005, Marcellan-Baraze et.al. 2011), por cuanto motivan procesos de enseñanza aprendizaje centrados en formar sujetos activos/as en la construcción de imágenes y discursos que circulan sobre sí mismos/as.

Por lo tanto cabe resaltar que atender una didáctica centrada en la expresión gráfica de niños y niñas debe considerar bajo el feminismo queer aquellas imágenes predominantes sobre de hombres y mujeres en la cultura visual. Por cuanto su consumo deriva en su expresión, requiriendo por tanto de procesos de deconstrucción que esclarezcan los criterios sancionados por la industria cultural para la construcción de cuerpos generizados que en definitiva se irrigan subrepticiamente en la mente de niños y niñas.

De allí entonces que la noción sujetos libres y autónomos preconizado por una expresión gráfica cimentada en los ideales modernos (Eisner, 1972; Lowenfeld \& Brittain, 1972, Lowenfeld, 1973; Lurcat, 1980; Cabanellas, 1980; Read, 1995; Sainz Martín, 2002), deben ser objeto de revisión crítica en la investigación de la educación de las artes por cuanto sus mecanismos de protección ante las influencias culturales de los mass-media se distanciaron de las imágenes generizadas de la Cultura Visual. En el entendido que una educación de las artes bajo una vertiente posmoderna aborda la crítica hacia desarrollo del yo y la supuesta libertad creadora sujeta a influencias de contenidos y significaciones de raza, clase y género emitidos por los mass-media (Egan, 1991; 2000; Giroux, 1999; Hernández, 2000; Matthews, 2002; Marín, 2003; Eisner, 2004; Wilson, Hurwitz, \& Wilson, 2004; Gardner, 2005; Hargreaves, 2005; Maeso, 2008).

\section{Metodología: "Crea tu propia personaje para video-juego"}

A raíz de lo anteriormente expuesto, el objetivo principal es abordado mediante una estrategia didáctica cimentada en la metodología cualitativa (Elliot, 1997; Eisner, 1998; Efland, 2002). Empleando durante el primer semestre académico del año 2014 al interior de un programa de formación de profesores/as en Artes Visuales en la ciudad de Talca en Chile una recogida de datos de acuerdo a los delineamientos definidos por la Investigación-Acción (Rodríguez et.al. 1996). En el entendido que la InvestigaciónAcción desde un comienzo fue un movimiento que surge en el contexto de colaboración entre profesores/as e investigadores/as en el desarrollo del currículo en el seno de un movimiento internacional de redes cooperativas de profesores/as formadores/as e investigadores/as educativos, para el desarrollo profesional de docentes (Elliot, 1997, 2000; Blández, 2000; Latorre, 2007).

Para ello se elabora un plan de acción centrado en la investigación cooperativa o colaborativa promoviendo una estrategia didáctica destinada a las prácticas iniciales de profesionales en formación en artes visuales para segundo ciclo de enseñanza general básica, según los niveles de aprendizaje de la matriz curricular básica en Chile (MINEDUC, 2015). Cuya actividad concreta consistirá en la representación grafica de 
una mujer protagonista para videojuegos elaborado por niños y niñas junto a sus relatos que bajo la teoría feminista queer (Butler, 1998, 2002, 2007) son susceptibles de ser analizadas debido a la transgresión de las identidades de género que ello implica.

\subsection{Investigación-Acción: Ciclo, Roles, Espacios Pedagógicos y Técnicas de recogida de datos}

Dicho mecanismo metodológico requiere enmarcar el diseño de acciones pedagógicas al interior de ciclos de investigación, configurando espacios pedagógicos en donde se desenvuelvan estratégicamente docente investigador, estudiantes en formación, niños y niñas al interior del sistema escolar. Por ende, se definen roles pedagógicos para quienes se encuentran implicados en el transcurso de la investigación.

Respecto de los ciclos de investigación cabe indicar que para un $1^{\circ}$ Ciclo de investigación se pretende abordar la transgresión de lo femenino entorno al concepto mujer bajo la teoría feminista queer, mediante la deconstrucción de las imágenes representativas de la mujer en los videojuegos consumidos por niños y niñas en contextos escolares.

De este modo, se diseña bajo una adaptación esquemática del modelo por Ciclos en Investigación-Acción, según Elliot (2000), un ciclo de investigación bajo un plan de acción. Que llevado a la práctica permite recoger aquellos datos susceptibles de ser analizados para de este modo obtener conclusiones y resultados de gran utilidad y base para el diseño de posteriores ciclos de investigación (Blández, 2000):

\begin{tabular}{|l|}
\hline $1^{\circ}$ Ciclo de \\
Investigación
\end{tabular}

Por otra parte, se definen los roles pedagógicos de Investigador Intermediario, Investigadores Participantes e Informantes Claves, asociados a docente investigador, profesionales en formación, niños y niñas, respectivamente: 
- Investigador/a intermediario/a (I.I.): Rol correspondiente al/la investigador/a responsable o docente responsable de la investigación, por cuanto coordina la formación práctica de profesionales de la educación en Artes Visuales.

- Investigadores/as participantes (I.P.): Rol que recae en los y las profesionales en formación cuya práctica en centros escolares permite articular su formación teórica al interior del programa de formación de profesores y profesoras en Artes Visuales.

- Informantes-Claves (I.C.): Rol destinado a Niños (I.C.m) y niñas (I.C.f.) insertos en los contextos escolares al interior de la asignatura de Artes Visuales, según matriz curricular básica en Chile. Y que en el caso particular de la presente investigación recae en 12 niños y 7 niñas distribuidos en los niveles $7^{\circ}$ y $8^{\circ}$ de enseñanza básica, correspondientes a cuatro centros de prácticas contemplados por el programa de formación de profesores y profesoras en Artes Visuales en la ciudad de Talca, Chile:

\begin{tabular}{|c|c|c|c|c|c|}
\hline \multirow[b]{2}{*}{$\mathrm{N}^{\circ}$} & \multirow{2}{*}{$\begin{array}{l}\text { Niveles de } \\
\text { Enseñanza } \\
\text { Segundo Ciclo } \\
\text { Básico }\end{array}$} & \multirow[b]{2}{*}{ Establecimientos Educacionales } & \multicolumn{2}{|c|}{ Género } & \multirow[b]{2}{*}{ Total } \\
\hline & & & Masculino & Femenino & \\
\hline \multirow[b]{2}{*}{1} & \multirow[b]{2}{*}{$7^{\circ}$ Básico } & Escuela Básica $n^{\circ} 1$ & 4 & ---- & 4 \\
\hline & & $\begin{array}{l}\text { Complejo Educacional Javiera } \\
\text { Carrera }\end{array}$ & 3 & 1 & 4 \\
\hline \multirow{2}{*}{2} & \multirow{2}{*}{$8^{\circ}$ Básico } & Juan Pía Marta & 3 & 4 & 7 \\
\hline & & Liceo Marta Donoso Espejo & 2 & 2 & 4 \\
\hline \multicolumn{3}{|c|}{ Total de Informantes-Claves } & 12 & 7 & $\begin{array}{l}1 \\
9\end{array}$ \\
\hline
\end{tabular}

Por ende, la investigación se desarrolla en dos espacios pedagógicos:

- Espacio pedagógico de formación del profesorado: Escenario en donde se reúnen el/la Investigador/a Intermediario/a e Investigadores/as Participantes al interior del programa de formación de profesores y profesoras en Artes Visuales. Siendo por lo tanto un espacio eminentemente teórico.

- Espacio pedagógico Escolar: Escenario correspondiente a los establecimientos educacionales o centros de prácticas profesionales a los cuales asisten Investigadores/as Participante e Informantes Claves en la asignatura de Artes Visuales. Conformando un espacio practico que dialoga con la formación teórica.

Respecto de las técnicas y métodos para conseguir pruebas, cabe señalar las siguientes, en la medida que permiten el registro, transcripción y tratamiento de información aportada por los/las informantes claves tras las intervenciones prácticas efectuada por investigadores/as participantes en los centros escolares:

- Dibujos: Correspondientes a la categoría de pruebas documentales (Blández, 2000) de mayor relevancia al ser elaborados por niños y niñas, por cuanto aportan datos que desprenden los conceptos de interés. 
- Datos fotográficos: Empleados como técnica de observación (Latorre, 2007) al ser consideradas documentos, artefactos o pruebas de la conducta humana. De hecho para Elliot (2000) corresponden a los datos que captan aspectos visuales de una situación, tales como el registro fotográfico de los dibujos realizados por cada informante clave, procediendo de esta forma en el tratamiento, ordenamiento y análisis de datos.

- Grabaciones audio-visuales y transcripciones: Por cuanto permiten el registro digital de la totalidad o parcialidad de las intervenciones prácticas mediante cámaras incorporadas en teléfonos móviles y/o cámaras digitales, tras previo consentimiento del centro escolar (Blández, 2000; Elliot, 2000; Latorre, 2007).

- Entrevista: Empleada con el objeto de obtener información sobre lo que niños y niñas opinan acerca del tema de interés y problema en estudio, a partir de una serie de preguntas cerradas y abiertas contestadas oralmente (Blández, 2000; Latorre, 2007)

\subsection{Identificación de la idea inicial}

La idea inicial se identifica en el contexto de formación de profesores y profesoras (noveles) especialistas en Artes Visuales. Formación relacionada con la necesaria articulación entre teoría y práctica, toda vez que la teoría es puesta en marcha en la práctica a través de los dispositivos didácticos, y la teoría es objeto de cuestionamiento a raíz de dicha práctica.

Entendiendo desde la teoría que el rol asumido por niños y niñas en calidad de consumidores de la Cultura Visual, concretamente de imágenes de mujer masculinizadas e hiperfeminizadas presentes en los videojuegos, promueven en la práctica educativa el desarrollo activo de niños y niñas como generadores/as de Cultura Visual bajo la perspectiva feminista queer.

\subsection{Reconocimiento y revisión de idea}

El enunciado en cuestión permite describir y explicar los hechos de la situación, bajo los siguientes términos:

\begin{tabular}{|c|c|}
\hline Descripción de los hechos de la situación & Explicación de los hechos de la situación \\
\hline $\begin{array}{l}\quad \text { Los procesos de digitalización de } \\
\text { imágenes representativas de la mujer en la } \sum \\
\text { Cibercultura transgrede las tradicionales } \\
\text { identidades de género, bajo una estética } \\
\text { hiperreal e hiperbolización del cuerpo. }\end{array}$ & $\begin{array}{r}\text { La industria cultural de los videojuegos } \\
\text { diversifican las posibilidades de consumo } \\
\text { hacia el público femenino atendiendo el } \\
\text { desequilibrio en las representaciones de género } \\
\text { mediante la masculinización de lo femenino y } \\
\text { su hiperfeminización. }\end{array}$ \\
\hline $\begin{array}{l}\text { El consumo de videojuegos por parte de } \\
\text { niños y niñas se desarrolla a partir de procesos } \\
\text { de socialización al interior de endogrupos } \\
\text { fuera de los contextos escolares. }\end{array}$ & $\begin{array}{r}\text { No se evidencia al interior de las bases } \\
\text { curriculares el desarrollo de reflexión crítica a } \\
\text { partir de productos de la Cultura Visual } \\
\text { destinada a niños y niñas, a través de } \\
\text { estrategias didácticas centradas en la expresión } \\
\text { gráfica. }\end{array}$ \\
\hline
\end{tabular}




\subsection{Hipótesis de trabajo}

La descripción de los hechos de la situación permite de este modo elaborar una hipótesis explicativa que alude a la relación entre los hechos de la situación problemática y otros factores que operan en su contexto:

"La expresión grafica elaborada por niños y niñas en proceso de escolarización entorno a imágenes de mujeres cuyas identidades transgreden la construcción tradicional de género, permiten esclarecer bajo la pedagogía queer la visibilización de la mujer en los videojuegos digitales de la Cultura Visual”.

\subsection{Estructura de plan general}

trabajo a cargo de un investigador intermediario en la asignatura de Didáctica de las Artes Visuales al interior del programa de formación de profesores y profesoras en Artes Visuales. Promoviendo en la sesión $n^{\circ} 15$ la simulación de intervenciones pedagógicas destinadas a los centros de prácticas. Instancia a partir de la cual los y las Investigadores/ as Participantes al interior del contexto escolar llevaron a cabo una estrategia didáctica de las artes visuales centrada en la expresión gráfica, bajo el siguiente titulo de actividad: "Crea tu propia personaje para videojuego". Exhibiendo previamente a cada grupo de curso el demo de un videojuego protagonizado por una mujer, con el objeto de solicitar a cada niño y niña la realización de un dibujo de mujer protagonista para videojuegos, bajo la indicación "Crea tu propia personaje para videojuego". Para posteriormente formular una serie de preguntas entre las cuales cabe destacar las siguientes: ¿En qué consiste tu video-juego? ¿Qué rol cumple la protagonista en el videojuego? ¿Cuáles son las características o rasgos personajes de tu protagonista?

Posteriormente durante las sesiones $\mathrm{n}^{\circ} 16 \mathrm{y} \mathrm{n}^{\circ} 17$ se presentaron los resultados de las intervenciones bajo un formato definido. Para finalmente en la sesión $n^{\circ} 18$ efectuar la retroalimentación del proceso.

\subsection{Reconocimiento y revisión de sus efectos}

Tras recoger y tratar semánticamente los registros orales y gráficos aportados por niños y niñas al interior de cada grupo curso, se establecen las siguientes categorías de análisis, las que permiten abordar la hipótesis explicativa anteriormente descrita y el objetivo principal de la investigación:

- Subversión de las identidades tradicionales de género al interior del marco performativo de sanción heterosexual: el bien y el mal.

- Estética predominante Japonesa y oposición binaria entre pares según género de informantes claves.

- La ficción como estructura narrativa de los videojuegos. 


\subsubsection{Subversión de las identidades tradicionales de género al interior del marco performativo de sanción heterosexual: el bien y el mal}

Los/las investigadores/as participantes I.P.(1) e I.P.(2) tras reunirse el 24 de Junio de 2014 en el primer espacio pedagógico con un grupo de informantes-claves conformado por 4 niños pertenecientes al $7^{\circ}$ año de la Escuela Básica 1, ubicada en la ciudad de Talca, recogen para su análisis las siguientes representaciones gráficas de figuras femeninas protagonistas para videojuegos: Yielene Guerrera, Tomasa, Gokuna y Soi.

Dibujos claramente influenciados por Ayumi, protagonista del videojuego Blade of Time (2012) exhibido al inicio de la actividad, en donde se aprecia su rol como heroína representante del bien en oposición a la avaricia y la venganza que encarnan sus rivales masculinos representantes el mal. A partir de lo cual los relatos y dibujos realizadas por cada niño evidencian oposición de conceptos binarios tales como el bien y el mal.

Destacando que tras la formulación de la pregunta ¿En qué consiste tu videojuego? los dibujos de figuras protagónicas femeninas atienden la subversión de las identidades tradicionales de género. En donde los niños en calidad de productores y consumidores de Cultura Visual le otorgan sentido a las representaciones de mujer al interior de estructuras narrativas que resaltan roles asociado a lo masculino, tales como la violencia, uso de armamento y acciones que derivan en la muerte del rival. Subvirtiendo de este modo, la sanción de normativas tradicionales de género asociadas a lo femenino, según los siguientes extractos de narraciones asociadas a sus respectivos dibujos:

I.P. (1): ¿En qué consiste tu video-juego?

I.C. m1: Una princesa guerrera, que los dioses estaban muertos y ella es la única que queda para combatir contra los malos y baja al mundo de los mortales y tiene que vencer los males.

I.C. m2: Éste el juego de la batalla de los perros mutantes...Esto consiste en una guerra porque estos perros están destruyendo el mundo con sus armas. Y ella es una del grupo que yo diseñé y el grupo de ellas, de las mujeres, tiene que combatir al grupo de los perros.

I.P. (2): Tiene poderes o armas especiales

I.C. m3: El Kameja

I.C. m4: Hay una explosión en una ciudad y salen unos monstruos aparece en un hospital y comienzan a matar a todos.

\subsubsection{Estética predominante Japonesa y oposición binaria entre pares según género de informantes claves}

El 11 de Junio de 2014 en el contexto escolar los y las investigadores/as participantes I.P.(2) e I.P.(3) se reúnen con un grupo de informantes claves conformado por cuatro niñas y tres niños pertenecientes al $8^{\circ}$ año básico del Colegio Juan Pía Marta, ubicado en la ciudad de Talca. Quienes tras visualizar el demo del videojuego Proyecto Zero (2002) protagonizado por Mikku, dibujan las siguientes figuras protagónicas para videojuegos: 


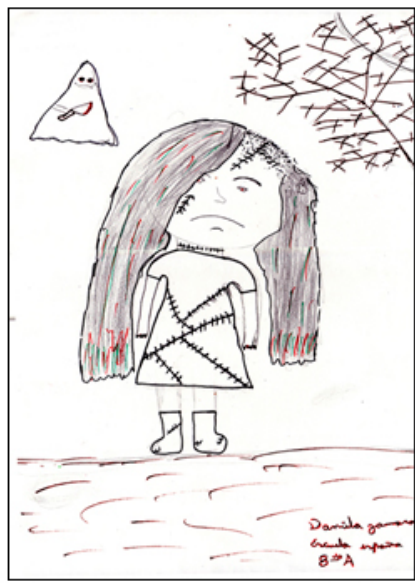

Figura 1.Informante Clave Femenina 1.

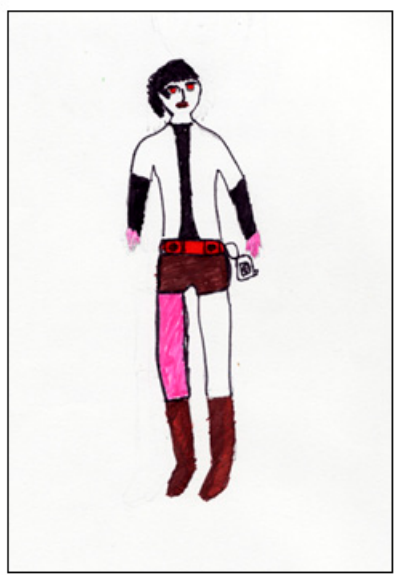

Figura 4. Informante Clave Masculino 5.

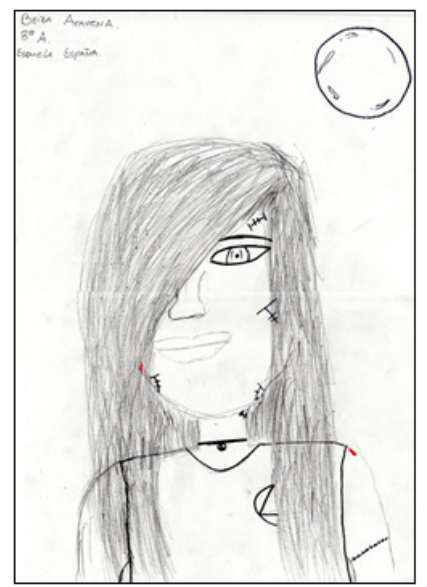

Figura 2. Informante Clave Femenina 2.

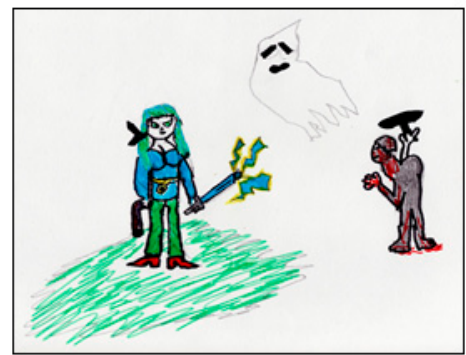

Figura 5. Informante Clave Masculino 6.

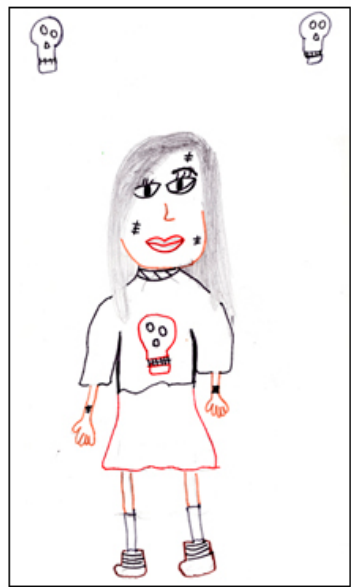

Figura 3. Informante Clave Femenina 3

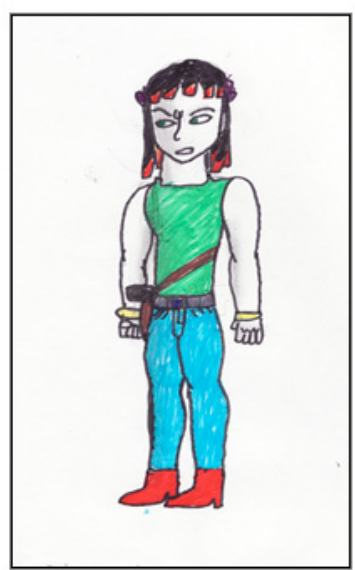

Figura 6. Informante Clave Masculino 7.

A partir de lo cual se percibe claramente que cada figura de mujer protagonista para videojuegos reflejan influencias de los aspectos físicos pertenecientes a Mikku. Sobresaliendo rasgos y características físicas orientales en rostros, peinados, vestimentas, armamentos y otros personajes, correspondientes a la estética denominada Japoanimación.

Rasgos físicos que otorgan una identidad homogénea a cada dibujo al interior del grupo curso. En donde niños y niñas en calidad de consumidores/as de productos culturales manifiestan la necesidad de sentirse al interior de un grupo de pares compartiendo las mismas inquietudes y preferencias estéticas (endogrupo) para poder entablar conversaciones y sentirse aceptados/as (Guarinos, 2011). Por cuanto les permite reconocerse entre sí como sujetos con los mismos gustos, compartiendo una serie de valores y principios que se manifiestan íntimamente al interior en este grupo. 
A partir de dicha influencia cabe resaltar una evidente oposición binaria al interior del grupo de informantes claves según género. Así por ejemplo, los dibujos realizados por las niñas (Fig.1, Fig.2 y Fig.3) emplean rasgos gráficos comunes tales como: lápiz negro para caracterizar un estilo de peinado ennegrecido sobre el rostro, dejando ver uno de los ojos y cicatrices sobre el rostro. Los niños en cambio (Fig.4, Fig.5y Fig.6) masculinizan sus figuras femeninas al igual que los criterios empleados por la industria de los videojuegos, cambiando los caracteres sexuales secundarios de la protagonista, conservando una identidad estereotipadamente masculina (Diez et.al.,2004).

\subsubsection{La ficción como estructura narrativa de los videojuegos}

$\mathrm{Al}$ igual que en los dibujos y relatos de informantes claves anteriormente analizados, la ficción es un elemento central tras la influencia de los videojuegos de referencia. De hecho dibujos y relatos reportan una secuencia de acontecimientos, relatos y sucesos ficticios que estructuran las narraciones de cada propuesta.

Así por ejemplo, atendiendo la pregunta ¿Qué rol cumple la protagonista en el videojuego? los I.P.(4) e I.P.(5) a cargo del $7^{\circ}$ básico del Complejo Educativo Javiera Carrera, ubicado en Talca nos presentan los siguientes dibujos y extractos de relatos efectuados por sus 4 informantes claves tras analizar el demo del videojuego Bayonetta (2009):

I.P.(4) e I.P.(5): ¿Qué rol cumple la protagonista en el videojuego?

I.C.m8: “...ella es una persona muy pobre, y resulta que encontró a la mamá y a la mamá la tenían aprisionada, y tiene que ir a buscarla"

I.C.m9: "Es una mujer, primero es una niña que vivía en una aldea y los enemigos de esa aldea mataron a la familia, a todos los que vivían allí y ella quedó con un tío. Y después ella se quiso vengar y ahora se quiere vengar de los que asesinaron a su familia"

I.C.m10: "Este es un juego de aventura y se trata de que ella quedó huérfana y una nueva raza aliens llega a su pueblo y es la única que se atreve a defender el pueblo

I.C.f4: "Ella se llama Ana, que defiende a todos los animales que están en peligro, que es como un como un zombie así, que mata a todos los malos y ella mata a los zombie para defenderlos".

De este modo el rol asumido por cada personaje, evidencian claras influencias de la estructura narrativa ficticia presente en Bayonetta (2009). A partir de la cual niños y niñas construyen mujeres protagonistas que sobreviven a tragedias familiares y colectivas, asumiendo roles conducentes a una serie de aventuras en función de la defensa y venganza ante hechos injustos.

Dichos relatos ficticios no pueden desligarse del tratamiento del cuerpo femenino otorgado a cada figura, cuya hiperbolización física y anatómica (Butler, 2007) en Bayonetta incide en la representación gráfica de armamentos, vestimentas funcionales y decorativas, ajustándose de esta manera a los requerimientos de una industria liderada preferentemente por hombres. Por cuanto las imágenes corporeizadas de mujer contrariamente a su visibilización equitativa, según Wajcman (2012), son atractivas a las fantasías de sus diseñadores masculinos. 
Por último, los/las investigadores/as participantes I.P.(6) e I.P.(7) a cargo de los/las informantes claves del $8^{\circ}$ año básico del Liceo Marta Donoso Espejo, de la ciudad de Talca, resaltan en los siguientes dibujos y sus respectivos extractos de relatos aquellos roles ficticios a partir del demo Tomb-Raider (2013):

I.P.(6) e I.P.(7): ¿Qué rol cumple la protagonista en el videojuego?

I.C.f9: "Ella escapo de su casa a los diez años por problemas familiares y trata de que ella tiene que enfrentarse a lo que el mundo le va a ...¿Cómo decirlo?...toda la maldad desde muy chica...ella es como llevada a sus ideas"

I.C.f10: "Es una niña que toda su familia trata de ayudarla y de comprenderla pero igual, pero en realidad no lo logra mucho porque ella está buscando a su familia de verdad para ver cómo es, conocerla..."

I.C.f12: "Es la protagonista....la llamaron de que le habían matado su familia, entonces vino un camión a recogerla y ella fue a cobrar venganza y a salvar a su hermano menor que había quedado herido"

I.C.f.13: "Es una sobreviviente de una invasión, es la única que queda y tiene que luchar contra los zombies para sobrevivir".

Extractos de relatos y sus respectivos dibujos influenciados claramente por el rol de Lara Croftt al interior del videojuego Tomb Raider. En donde cada nueva figura protagonista enfrenta la maldad del mundo, ayudando a los demás, cobrando venganza y luchando contra zombies. Indicándonos de este modo que la mujer, en lugar de ser objeto de rescate, son protagonistas y fuerza motriz de la trama del juego, en el entendido que en origen Tomb Raider se separó del patrón familiar de los roles tradicionales de lo femenino, según Mikula (2003).

Respecto de la representación gráfica cabe destacar que cada nueva imagen de mujer posee vestimentas y armamentos que no se condicen con los estereotipos tradicionales del género femenino, sino, más bien con representaciones de mujeres con rasgos físicos fuertes, que les permiten luchar y disparar gracias a sus habilidades gimnásticas, al igual que Lara: "Lara totes a gun as she navigates a hostile landscape fraught with danger" (Kennedy, 2002). Por cuanto la transgresión de la imagen tradicional de la mujer en los videojuegos digitales consiste en la migración de lo femenino a espacios tradicionalmente masculinizados.

\section{Conclusiones}

Atendiendo la hipótesis en acción, cabe señalar a raíz de los dibujos realizados por niños y niñas al interior de sus respectivos grupos de cursos, que la transgresión en la construcción de lo femenino acontece a través de su desplazamiento hacia lo masculino. Lo que significa en definitiva, según lo planteado por Imbert (2008) una migración de lo femenino al terreno de acción e hiperbolización del cuerpo (Butler, 2002) promovido por una industria pensada por varones y destinada a los varones. Sancionando una cultura y tecnología preconizada por el Tecnofeminismo (Wacjman, 2012), bajo la heteronormatividad como marco regulatorio en la construcción de imágenes representativas de mujeres y hombres en los videojuegos. 
En donde la transgresión consistiría en modificar aspectos formales de carácter estético en la construcción digital de la mujer. Cuyo contenido revitaliza espacios tradicionalmente ocupados por hombres (cultura macho). Dando cabida a personajes tales como Ayumi, Mikku, Bayonnetta y Lara Croftt, resignificadas por nuevas protagonistas que nos revelan mujeres cuyos roles, rasgos y características acontecen dentro de narraciones ficticias que reproducen las emitidas por los videojuegos. En donde la mujer se desenvuelve performativamente bajo criterios masculinos. Concluyendo al igual que Volnovich (2010) que el grado de innovación obedece tan solo a sus alcances de mercado y audiencias que incluyen a niñas como videojugadoras al igual que los niños como videojugadores.

Por lo tanto, promover actividades didácticas cimentadas en la pedagogía queer nos aproximan al debate y discusión centrada en las posibilidades de visualizar el género más allá de su binarismo tradicional. En donde la creación de una personaje protagonista para videojuegos a través de la expresión grafica, nos evidencia normas de mercado asumidas por niños y niñas en contextos escolares. Lo que ameritan proponer didácticas de las artes visuales en donde el género sea objeto de subversión al interior de la sala de clases.

\section{Referencias}

Blández, J. (2000). La investigación-acción: Un reto para el profesorado. Guía práctica para grupos de trabajo, seminarios y equipos de investigación. Barcelona: INDE Publicaciones.

Buckingham, D.(2000). Crecer en la era de los medios electrónicos. España: Morata y Paideia.

Butler, J. (2007). El género en disputa. El Feminismo y subversión de la identidad. Barcelona: Paidós.

---- (2002). Cuerpos que importan. Sobre los límites materiales y discursivos del sexo. Buenos Aires: Paidós.

---- (1998). Actos performativos y constitución del género: un ensayo sobre fenomenología y teoría feminista. Debate feminista, 18(9), pp. 296-314.

Cassell, J. \& Jenkins, H. (2000). From Barbie to Mortal Kombat: gender and computer games. United States of América: The MIT Press.

Cortés, L. (2014). La cultura visual como contenido vital de la educación artística en Chile: Las heroínas como recurso didáctico del siglo XXI (Doctoral dissertation, Universidad Complutense de Madrid). Recuperado de http://eprints.ucm. es/24551/1/T35139.pdf

Darley, A. (2002). Cultura Visual Digital. Espectáculo y nuevos géneros en los medios de comunicación. Barcelona: Paídos.

Díez , E., Terrón, E., García, M., Rojo, J., Cano, R., Blanco, D. y Terrón, M. (2004). La diferencia sexual en el análisis de los videojuegos. Madrid: CIDE: Instituto de la Mujer.

Elliot, J. (2000). El cambio educativo desde la investigación-acción. Madrid: Morata

---- (1997): La investigación-acción en educación. Madrid: Morata. 
Fantone, L. (2003). Final Fantasies: Virtual Women's Bodies. Feminist Theory, vol. $4,51-72$.

Gardner, H. (2005). Arte mente y cerebro. Barcelona: Paidós.

Gil-Juarez, A., Vitores, A., y Feliu, J. (2010). Performatividad tecnológica de género: explorando la brecha digital en el mundo del videojuego. Quaderns de psicología, vol. 12, 209-226.

Guarinos, V.(2011) La edad adolescente de la mujer. Estereotipos y prototipos audiovisuales femeninos adolescentes en la propuesta de Disney Channel. Revista Comunicación y Medios, vol. 23, 37-46.

Haraway,D.(2004).Testigo_Modest@Segundo_Milenio.HombreHembra@_Conoce_ Oncoratón ${ }^{\circledR}$. Feminismo y tecnociencia. Barcelona: UOC.

Hernández, F. (2000). Educación y Cultura Visual. Barcelona: Octaedro.

Imbert, G. (2008). El transformismo televisivo. Madrid: Cátedra

III Congreso de arte infantil, U.C.M. (2005). Arte infantil y cultura visual. Madrid: Eneida.

Kennedy, H.(2002). Lara Croft: feminist icon or cyberbimbo? On the limits of textual analysis. Game Studies: International Journal of Computer Games Research, vol. 2, n.2.

King, G. \& Krzywinska, T. (2006). Tomb raiders and space invaders: Videogame forms and contexts. New York: IB Tauris.

Latorre, A. (2007) La investigación-acción. Conocer y cambiar la práctica educativa. Barcelona: Graó.

Levy, P. (2007). Cibercultura. Informe al Consejo de Europa. Barcelona: Anthropos.

Marcellan-Baraze, I., Calvelhe, L., Agirre, I.; Arriaga, A.(2013). Estudio sobre jóvenes productores de cultura visual: evidencias de la brecha entre la escuela y la juventud. Arte, Individuo y Sociedad, vol. 25, n. 3, 524-535.

Mendizábal, R.(2004): Máquinas de pensar. Video juegos, representaciones y simulaciones del poder. Quito: Universidad Andina Simón Bolivar, Ecuador.

Mikula, M. (2003). Gender and Videogames: the political valency of Lara Croft. Continuum: Journal of Media \& Cultural Studies, vol. 17, n.1, 79-87

Nead, L. (1992). El desnudo femenino: Arte, obscenidad y sexualidad. Madrid: Tecnos.

Rodríguez, G., Gil, J., García, E. (1996). Metodología de la investigación cualitativa. Granada: Aljibe.

Rubin, G. (2008). Continuidad y cambio. Género y culturas de la tecnología en el trabajo Telos. Cuadernos de comunicación e innovación, vol. 74, 48-55

Schultz, M. (2006). Filosofía y Producciones Digitales. Buenos. Aires: Alfagrama.

Torres, O. y Salazar, S. (2006). La estatura del derecho: igualdad, participación ciudadana y percepción de los medios en niños, niñas y adolescentes chilenos. Santiago de Chile: Universidad de Chile, Instituto de la Comunicación e Imagen.

Vitta, M. (2003). El sistema de las imágenes. Estética de las representaciones cotidianas. Barcelona: Paídos.

Volnovich, J. C. (2008) El sexo oculto de los videojuegos. Red Mercosur de Facultades de Diseño. Terceras Jornadas Interuniversitarias. 154-161. 
Wajcman, J. (2012). TIC e inequidad: ¿ganancias en red para las mujeres? Revista Educación y Pedagogía, 62, 117-134. Recuperado de http://aprendeenlinea.udea. edu.co/revistas/index.php/revistaeyp/article/viewFile/14198/12541

---- (2008) Continuidad y cambio. Género y culturas de la tecnología en el trabajo Telos. Cuadernos de comunicación e innovación, vol. 74, 48-55

Zafra, R. (2015). Salir del armario: pedagogías 'queer' y otras formas de abordar la identidad sexual en el aula. Recuperado de http://espacio.fundaciontelefonica. com/2015/03/05/salir-del-armario-pedagogias-queer-y-otras-formas-de-abordarla-identidad-sexual-en-el-aula/ 